\title{
Commentary
}

\section{Binders: In a nutshell}

The essential features of maxillo-nasal dysplasia were initially described by Noyes in $1939^{[1]}$, although it was Binder who first defined it as a distinct clinical syndrome. He reported on three cases and recorded six specific characteristics which are:

- Arhinoid face.

- Abnormal position of nasal bones.

- Inter-maxillary hypoplasia with associated malocclusion.

- Reduced or absent anterior nasal spine.

- Atrophy of nasal mucosa.

- Absence of frontal sinus (not obligatory).

Individuals with Binder's syndrome have a characteristic appearance that is easily recognizable:

1. The mid-face profile is hypoplastic

2. The nose is flattened

3. The upper lip is convex with a broad philtrum

4. The nostrils are typically crescent or semi-lunar in shape due to the short collumela

5. A deep fold or fossa occurs between the upper lip and the nose, resulting in an acute nasolabial angle.

Cephalometrically, there is a reduced sella-nasion distance and the length of the maxilla measured from the anterior surface to the posterior nasal spine is reduced, partly due to the midface skeletal defect that extends from the inferior rim of the piriform aperture beyond the apical base. Binder's Syndrome can also be combined with other malformations. Olow-Nordenram and Radberg reported 44.2 per cent of a study sample to

\begin{tabular}{|l|l|}
\multicolumn{3}{c|}{ Access this article online } \\
\hline Quick Response Code: & \\
\hline
\end{tabular}

have malformation of cervical vertebrae ${ }^{|2|}$ The association with pseudo-mandibular prognathism has also been described. ${ }^{[3]}$ In the most severe cases, the syndrome is associated with true mandibular prognathism, which requires combined orthodontic and surgical treatment..$^{[4]}$

The aims of treatment remain:

- Relieve crowding;

- Level and align upper and lower arches;

- Obtain positive overjet and overbite;

- Correct the lower centre line;

- Co-ordinate the arches;

- Obtain a Class I molar relationship.

Ian Munro's work on treatment of these individual still remains our standard reference..$^{[5]}$

\section{REFERENCES}

1. Noyes FB. Case report. Angle Orthod 1939;9:160-5.

2. Olow-Norderam M, Radberg CT. Maxillonasal dysplasia (Binder syndrome) and associated malformations of the cervical spine. Acta Radiologica Diagnosis 1984; 25:353-60.

3. McCollum AGH, Wolford LM. Binder Syndrome: Literature review and long-term follow-up on two cases. Adult Orthod Orthognath Surg 1998;13:45-58.

4. Olow-Nordenram M, Thilander B. The craniofacial morphology in persons with maxillonasal dysplasia (Binder syndrome). Am J Orthod Dentofac Orthop 1989;95:148-58.

5. Munro IR Maxillonasal dysplasia (Binder's syndrome). Plas Reconst Surg 1979;41:536-42.

\section{Bhattacharya S., Uppadhayya D. N. ${ }^{1}$}

Editor, IJPS, C-907, Mahanagar, Lucknow

${ }^{1}$ Consultant Plastic Surgery, Vivekananda Hospital, Lucknow

Email: surajitbh@yahoo.co.in

How to cite this article: Bhattacharya S, Uppadhayya DN.

Binders: In a nutshell. Indian J Plast Surg 2012;45:67. 